\title{
Syringe Device
}

National Cancer Institute

\section{Source}

National Cancer Institute. Syringe Device. NCI Thesaurus. Code C50207.

A device designed as a rigid cylinder with a plunger at one end and a delivery opening at the other. 